\title{
The effects of urbanization on global Plasmodium vivax malaria transmission
}

\author{
Qiuyin Qi ${ }^{*}$, Carlos A Guerra ${ }^{2}$, Catherine L Moyes ${ }^{2}$, Iqbal R F Elyazar ${ }^{3}$, Peter W Gething ${ }^{2}$, Simon I Hay ${ }^{2,5}$ \\ and Andrew J Tatem ${ }^{1,4,5}$
}

\begin{abstract}
Background: Many recent studies have examined the impact of urbanization on Plasmodium falciparum malaria endemicity and found a general trend of reduced transmission in urban areas. However, none has examined the effect of urbanization on Plasmodium vivax malaria, which is the most widely distributed malaria species and can also cause severe clinical syndromes in humans. In this study, a set of 10,003 community-based P. vivax parasite rate (PvPR) surveys are used to explore the relationships between PvPR in urban and rural settings.
\end{abstract}

Methods: The PvPR surveys were overlaid onto a map of global urban extents to derive an urban/rural assignment. The differences in PVPR values between urban and rural areas were then examined. Groups of PVPR surveys inside individual city extents (urban) and surrounding areas (rural) were identified to examine the local variations in PVPR values. Finally, the relationships of PvPR between urban and rural areas within the ranges of 41 dominant Anopheles vectors were examined.

Results: Significantly higher PVPR values in rural areas were found globally. The relationship was consistent at continental scales when focusing on Africa and Asia only, but in the Americas, significantly lower values of PvPR in rural areas were found, though the numbers of surveys were small. Moreover, except for the countries in the Americas, the same trends were found at national scales in African and Asian countries, with significantly lower values of PVPR in urban areas. However, the patterns at city scales among 20 specific cities where sufficient data were available were less clear, with seven cities having significantly lower PVPR values in urban areas and two cities showing significantly lower PVPR in rural areas. The urban-rural PVPR differences within the ranges of the dominant Anopheles vectors were generally, in agreement with the regional patterns found.

Conclusions: Except for the Americas, the patterns of significantly lower P. vivax transmission in urban areas have been found globally, regionally, nationally and by dominant vector species here, following trends observed previously for $P$. falciparum. To further understand these patterns, more epidemiological, entomological and parasitological analyses of the disease at smaller spatial scales are needed.

Keywords: Plasmodium vivax, Urbanization, Dominant Anopheles vectors, Mapping

\section{Background}

The world population has undergone unprecedented growth along with rapid urbanization. Slightly more than $50 \%$ of the population (3.6 billion) is now living in urban areas compared to only $30 \%$ (0.7 billion) in 1950 [1]. By 2050 , it is projected that urban dwellers will account for approximately $67 \%$ (6.3 billion) of the world total

\footnotetext{
*Correspondence: qiuyinqi@ufl.edu

'Department of Geography and Emerging Pathogens Institute, University of Florida, Gainesville, FL, USA

Full list of author information is available at the end of the article
}

population, while most of the estimated growth will be concentrated in less developed regions, particularly in Asia and Africa [1]. These substantial transitions have significant public health implications associated with changes in the social and physical environment and access to public health services [2-6].

Although large heterogeneity exists, it is commonly accepted that the process of urbanization reduces malaria transmission, primarily because urban environments (e.g. the lack of suitable breeding sites, the pollution of existing larval habitats, etc.) are generally unsuitable for

\section{Biomed Central}

(c) 2012 Qi et al.; licensee BioMed Central Ltd. This is an Open Access article distributed under the terms of the Creative Commons Attribution License (http://creativecommons.org/licenses/by/2.0), which permits unrestricted use, distribution, and reproduction in any medium, provided the original work is properly cited. 
malaria vectors [7-9]. Other explanations include better access to health care services and an increased ratio of humans to mosquitoes $[7,10,11]$. However, there is concern regarding urban malaria in less developed regions, typically those undergoing rapid and unprecedented urbanization $[12,13]$.

Between the two dominant parasite species of human malaria, Plasmodium falciparum has attracted the focus of most research because of its high mortality and intensive transmission in Africa [14]. Plasmodium vivax malaria, in contrast, is commonly considered as a "benign" infection and largely overlooked by researchers, government, and funding agencies. Increasing evidence has shown that $P$. vivax is neither rare nor benign, however. It is estimated that 2.85 billion people were at risk of $P$. vivax infection in 2009, with $91 \%$ (2.59 billion) of them living in Central and South East Asia [15], and that $P$. vivax is the most widely distributed (geographically) malaria species of humans. Furthermore, although the infection with $P$. vivax malaria is rarely directly fatal, it can cause severe clinical syndromes $[16,17]$.

Recent studies have examined the impact of urbanization on $P$. falciparum malaria endemicity and disease burden estimation [7-9,13,18]. Various urban extent maps have been used to compare the differences in $P$. falciparum malaria endemicity between urban settlements and rural areas [18]; exclude the urban extents of cities identified as malaria free in the mapping of malaria transmission limits [19,20]; downgrade endemic classes in estimates of malaria burden $[9,21]$; and predict $P$. falciparum malaria endemicity based on geo-statistical models [22,23]. However, according to our best knowledge, no known research has examined the effect of urbanization on $P$. vivax malaria over similarly large scales. In addition, the regions of highest $P$. vivax transmission in Asia are composed of a considerably greater range of vector species and species complexes than seen in Africa, where P. falciparum transmission is principally concentrated [24-27], and urbanization may impact each of these vector species differently, dependent on their preferences and bionomics. For example, Anopheles culicifacies was reported to be the vector responsible for 60-65\% malaria cases in urban environments of India [28] and shows significant environment tolerance and adaptability [29,30], while larvae of Anopheles stephensi were found in various domestic containers and collections of water related to construction and industrial sites in cities [31,32]. Therefore, there is a need to examine the effects of urbanization on $P$. vivax transmission by dominant vector species to discern whether differential impacts are evident.

Here geo-referenced $P$. vivax parasite rate $(P \nu \mathrm{PR})$ surveys and urban extent maps are integrated to examine the impact of urbanization on $P$. vivax malaria transmission at various spatial scales (global, regional, national and at the city level). Furthermore, distribution maps of dominant Anopheles vectors are used to explore the relationships between urbanization, Anopheles vectors and $P$. vivax malaria transmission.

\section{Methods}

\section{Datasets}

\section{The MAP PVPR database}

As with $P$. falciparum malaria, parasite rate (PR) is the most commonly reported and consistent metric of P. vivax malaria endemicity [33]. A total of 10,003 community-based $P$. vivax parasite rate $(P v \mathrm{PR})$ surveys taken between 1985 and 2010 were obtained by the Malaria Atlas Project (MAP [34]). The logistically intensive process of searching for, identifying and geo-locating the $P \nu$ PR surveys has been documented elsewhere [35]. All these $P v$ PR surveys were geo-referenced to precise locations and not duplicated within three months at the same site. A summary of some of the key features of the $P \nu$ PR survey data is presented in Table 1 . Of the surveys, 410 (4.1\%) were in the Americas, 1,651 (16.5\%) in Africa, Saudi Arabia and Yemen (Africa+), and 7,942 (79.4\%) in Central and South East Asia (Asia+). Approximately half (51\%) of the $P \nu \mathrm{PR}$ values are zero and the majority of the surveys were undertaken after 2000. The sample sizes of these surveys varies, with most of them $(76 \%)$ are being larger than 50 . Among the $95 P$. vivax malaria endemic countries ( $P v \mathrm{MECs})$ [15], $P v \mathrm{PR}$ data were available for 53 (12 in the Americas, 19 in Africa+ and 22 in Asia+). There are 8,588 discrete $P \nu$ PR survey locations and the distribution of them are shown in Figure 1, overlaid on the international limits of $P$. vivax malaria transmission [15], with most of the survey points located in Southeast Asia and the Horn of Africa.

\section{Global urban map}

Although urbanization has been one of the most important transformations of our world for decades, there is still little consensus on the definitions of what consists an urban area and urbanization among national and international bodies [2]. Such ambiguity has lead to the construction of several global urban maps (e.g., Digital Chart of the World (DCW) [36], Global Rural Urban Mapping Project (GRUMP) [37], Advanced Very High Resolution Radiometer (AVHRR) Global Land Cover Classification urban land cover class [38], Defense Meteorological Satellite Program-Operational Linescan System (DMSP-OLS) [39], and Moderate Resolution Imaging Spectroradiometer (MODIS) Land Cover Product Binary Data $[40,41]$ ) derived from satellite imagery [42]. As discussed in Tatem et al. [42], all of these global urban maps demonstrated a different range of 
Table 1 Summary of the PvPR surveys by region

\begin{tabular}{|c|c|c|c|c|}
\hline & Africa+ & Americas & Asia+ & Total \\
\hline \multicolumn{5}{|l|}{ PvPR values } \\
\hline Number of zero records & 1,299 & 193 & 3,631 & 5,123 \\
\hline Mean PVPR (\%) & 0.60 & 3.25 & 3.55 & 3.05 \\
\hline Median PVPR (\%) & 0.00 & 0.61 & 0.51 & 0.00 \\
\hline \multicolumn{5}{|l|}{ Time period of surveys } \\
\hline 1985-1999 & 225 & 223 & 1,328 & 1,776 \\
\hline $2000-2010$ & 1,426 & 187 & 6,614 & 8,227 \\
\hline \multicolumn{5}{|l|}{ Sample size } \\
\hline $1-50$ & 911 & 151 & 1,316 & 2,378 \\
\hline$>50$ & 740 & 259 & 6,626 & 7,625 \\
\hline Median (IQR) & $48(34-109)$ & $87(37-210)$ & $120(67-281)$ & $107(53-236)$ \\
\hline \multicolumn{5}{|l|}{ Records of surveys } \\
\hline GRUMP-UE defined urban & 444 & 61 & 755 & 1,260 \\
\hline GRUMP-UE defined rural & 1,203 & 349 & 7,241 & 8,743 \\
\hline Discrete geographic locations & 1,424 & 291 & 6,873 & 8,588 \\
\hline Total & 1,651 & 410 & 7,942 & 10,003 \\
\hline
\end{tabular}

Africa+ =Africa, Saudi Arabia and Yemen; Asia+ =Central and South East Asia.

inaccuracies and limitations, however, the GRUMP urban extent map was considered to be most accurate in matching original urban assignments of $P$. falciparum malaria surveys [18]. Therefore, the GRUMP urban extent (GRUMP-UE) map was used here to distinguish $P v$ PR surveys taken in urban areas from those in rural areas. This urban extent map was developed by the Centre for International Earth Science Information Network (CIESIN) at $1 \mathrm{~km} \times 1 \mathrm{~km}$ spatial resolution in 2004, utilizing information from satellite night-time lights (NTL), Landsat satellite sensor imagery and other geographical data [43].

\section{Dominant Anopheles vector maps}

The distributions and bionomics of dominant Anopheles vectors play an important role in malaria transmission and are the targets of vector control [44]. Vector species normally display a range of ecological and behavioural characteristics. For example, unlike other malaria vectors, an urban environment is favored by the "urban vector" Anopheles stephensi [45]. To assess the impact of urbanization on $P$. vivax malaria transmission by dominant Anopheles vectors, expert-opinion distribution maps of global dominant vector species (DVS) of malaria were obtained from the Malaria Atlas Project [25-27,34]. These maps were constructed through exhaustive searches of literature and refinement through opinion and experience by Anopheles experts [27]. A total of 41 maps of DVS were available, of which, 19 were in the Asia-Pacific region [26], 13 in Africa, Europe and the Middle East [25], and nine in the Americas [27].

\section{Analysis}

Urbanization and $P$. vivax malaria transmission

To quantify the patterns of $P$. vivax malaria transmission between urban and rural areas at global, regional and national scales, sets of spatially and temporally associated urban-rural pairs of $P v P R$ values were obtained and tested. Firstly, all the geo-referenced $P \nu$ PR surveys were overlaid onto the GRUMP-UE map to derive an urban/rural assignment. Following previous approaches [18], for each $P \nu \mathrm{PR}$ survey assigned as urban, all the rural $P v$ PR surveys taken within $100 \mathrm{~km}$ and five years were identified. Then, the identified rural $P \nu \mathrm{PR}$ values were averaged and assigned to that urban $P v \mathrm{PR}$ survey to make spatially and temporally associated urban-rural $P v$ PR value pairs [18]. Given the highly skewed distribution of $P \nu \mathrm{PR}$ values in the MAP database [35], the Wilcoxon Signed Rank [46], a nonparametric test for paired variables, was used to determine if significant differences between $P v$ PR values in urban and rural areas existed. These tests were undertaken globally, by region (Africa+, Americas, Asia+) and by country (those for which at least ten urban-rural $P v \mathrm{PR}$ survey pairs existed) to examine if the patterns of $P$. vivax malaria transmission between urban and rural areas were significant.

As the choice of spatial and temporal limits $(100 \mathrm{~km}$ and five years) is arbitrary in obtaining urban-rural pairs of $P \nu \mathrm{PR}$ values, a robustness analysis was conducted. Sets of urban-rural $P \nu \mathrm{PR}$ pairs were obtained through applying various spatial and temporal limits $(100 \mathrm{~km}$ and two years; $50 \mathrm{~km}$ and five years; $50 \mathrm{~km}$ and two years), and tested under the Wilcoxon Signed Rank test, respectively. In addition, the mean number of rural 


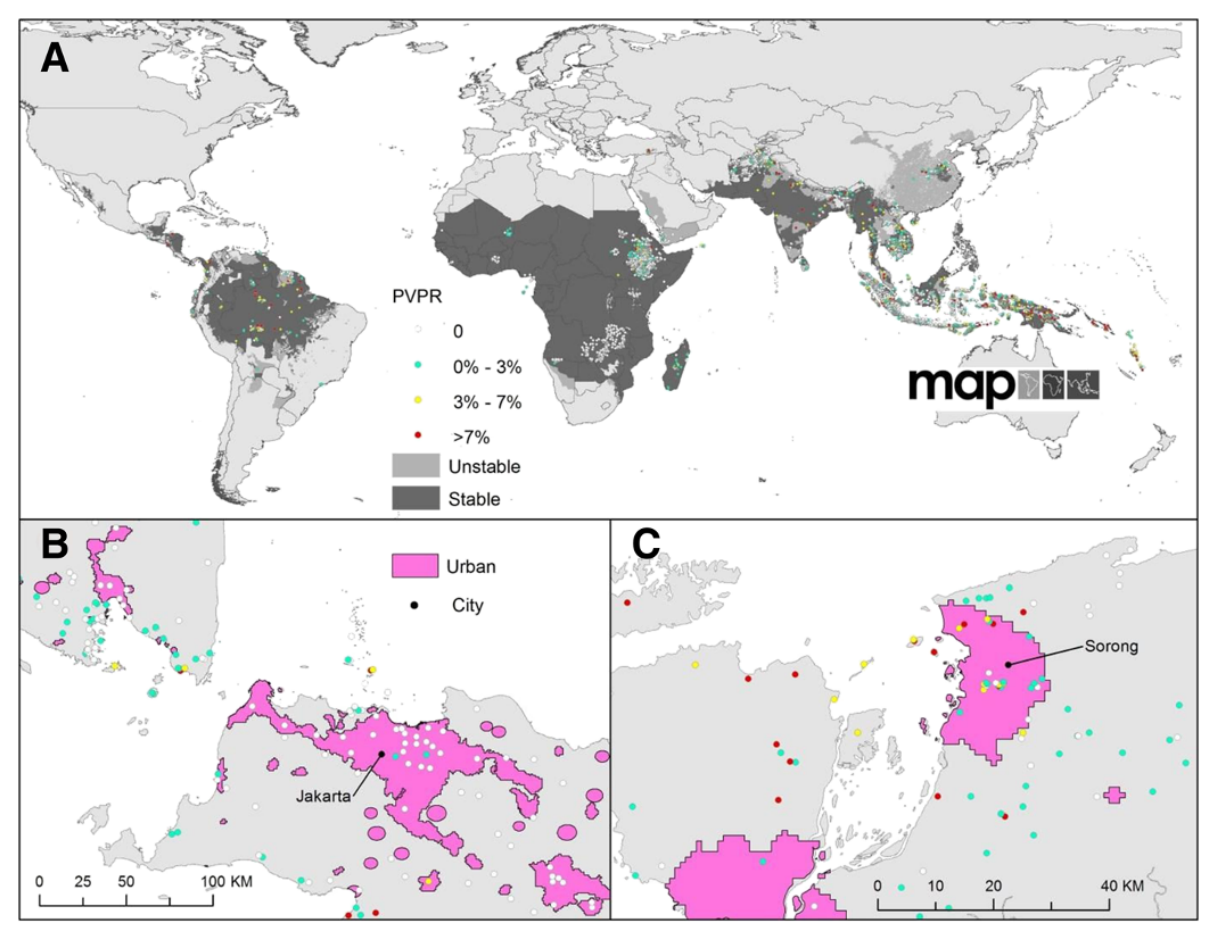

Figure 1 The global spatial limits of $P$. vivax malaria transmission in 2009 [15]. Panel A shows the spatial limits of $P$. vivax malaria risk defined by $P$. vivax annual parasite incidence (PvAPI) data. Areas were defined as stable (dark grey, where PvAPI $\geq 0.1$ per 1,000 pa), unstable (medium grey, where $P v A P I<0.1$ per 1,000 pa) and no risk (light grey, where $P v A P I=0$ per 1,000 pa). The community-based $P v P R$ surveys are plotted and colored based on their values (red, where PvPR $>7 \%$; yellow, $3 \%<P v P R<7 \%$; light blue, $P v P R<3 \%$ ) with zero-valued surveys shown in white. Panel $\mathbf{B}$ and Panel $\mathbf{C}$ are close-ups for regions with plenty of PvPR surveys with Panel B showing the area around Jakarta, Indonesia and Panel $\mathbf{C}$ showing the areas around Sorong, Indonesia.

surveys paired to each urban survey and the overlap rate ( $\sum$ number of rural surveys paired to each urban survey/total number of rural surveys) for each spatial and temporal limit were calculated to assess the effects of overlapping rural surveys in the sample pairs.

To examine local variations (city scale) in $P v \mathrm{PR}$, groups of $P \nu \mathrm{PR}$ surveys inside individual city extents (urban) and surrounding areas (rural) were identified and tested. Cities where more than eight $P \nu \mathrm{PR}$ surveys (to provide a reasonable number of cities for testing) fell inside their urban extents were first identified. For each city, rural $P v$ PR surveys that fell within $100 \mathrm{~km}$ of the centroid of the urban extent were found and assigned to that city. Following this, for each city, $P \nu \mathrm{PR}$ values within its urban extent and surrounding rural area were compared and tested using the Wilcoxon Rank Sum test.

\section{Dominant Anopheles vectors}

The impact of urbanization on malaria endemicity may vary by dominant Anopheles vectors of human malaria. To test this, $P \nu \mathrm{PR}$ values between urban and rural areas within the extents of 41 dominant Anopheles vector were examined.

Sets of spatially and temporally associated urban-rural pairs of $P \nu \mathrm{PR}$ values within the extents of each dominant
Anopheles vector were extracted and tested separately. The geo-referenced $P v \mathrm{PR}$ surveys were firstly overlaid onto the GRUMP-UE map to derive an urban/rural assignment. For each dominant Anopheles vector, all the $P \nu \mathrm{PR}$ surveys that fell within its extent were extracted. For each urban $P \nu$ PR survey, all of the rural $P v$ PR surveys taken within $100 \mathrm{~km}$ and five years were again identified, averaged and assigned to that urban $P v \mathrm{PR}$ survey to make a set of spatially and temporally associated urban-rural $P \nu$ PR value pairs [18]. This set of urbanrural $P v \mathrm{PR}$ value pairs were then subject to the Wilcoxon Signed Rank test to determine if significant differences in $P \nu$ PR between urban and rural areas existed.

\section{Results}

\section{Urbanization and $P$. vivax malaria transmission}

Among the $P \nu$ PR surveys, 1,260 were classified as urban and 8,743 were classified as rural based on the GRUMPUE map (Table 1). The mean sample size was 278 for the urban surveys and 230 for the rural surveys, which are comparable. Table 2 shows the results of the Wilcoxon Signed Rank tests between urban and rural pairs of $P v$ PR values defined by GRUMP-UE. Significantly higher $P \nu \mathrm{PR}$ values in rural areas were found globally and in the Africa+ and Asia+ regions, while in the 
Table 2 Results of Wilcoxon Signed Rank tests on PvPR values between GRUMP-UE defined urban (U) and rural (R) survey pairs for countries, regions and the World

\begin{tabular}{|c|c|c|c|c|c|c|c|}
\hline \multirow[t]{2}{*}{ Region } & \multirow{2}{*}{$\begin{array}{l}\text { No. } \\
\text { pairs }\end{array}$} & \multicolumn{2}{|c|}{$U>R$} & \multicolumn{2}{|c|}{$\mathbf{U}<\mathbf{R}$} & \multirow[t]{2}{*}{$\mathrm{Z}$} & \multirow[t]{2}{*}{ P-value } \\
\hline & & No. pairs & Rank sum & No. pairs & Rank sum & & \\
\hline Africa+ & 428 & 33 & 1,432 & 86 & 5,708 & -5.670 & $<0.001^{* * *}$ \\
\hline Ethiopia & 80 & 18 & 587 & 61 & 2,573 & -4.853 & $<0.001^{* * *}$ \\
\hline Sudan & 192 & 7 & 47 & 9 & 89 & -1.086 & 0.286 \\
\hline Yemen & 35 & 7 & 41 & 13 & 169 & -2.389 & $0.018^{* *}$ \\
\hline Other countries & 13 & 1 & 2 & 3 & 8 & -1.095 & 0.361 \\
\hline Americas & 49 & 23 & 636 & 19 & 263 & 2.307 & $0.021^{* *}$ \\
\hline Brazil & 22 & 15 & 135 & 3 & 36 & 2.156 & $0.032^{* *}$ \\
\hline Mexico & 10 & 1 & 10 & 9 & 45 & -1.784 & $0.067^{*}$ \\
\hline Other countries & 17 & 7 & 72 & 7 & 33 & 1.224 & 0.232 \\
\hline Asia+ & 712 & 127 & 50,971 & 517 & 156,719 & -11.194 & $<0.001^{* * *}$ \\
\hline Afghanistan & 68 & 23 & 1,023 & 42 & 1,122 & -0.323 & 0.749 \\
\hline Bangladesh & 27 & 1 & 27 & 26 & 351 & -3.892 & $<0.001^{* * *}$ \\
\hline China & 26 & 8 & 146 & 18 & 205 & -0.749 & 0.461 \\
\hline Indonesia & 462 & 74 & 18,926 & 328 & 62,077 & -9.256 & $<0.001^{* * *}$ \\
\hline India & 26 & 4 & 60 & 22 & 291 & -2.933 & $0.003^{* * *}$ \\
\hline Cambodia & 12 & 1 & 6 & 11 & 72 & -2.589 & $0.007^{* * *}$ \\
\hline Nepal & 18 & 2 & 35 & 16 & 136 & -2.199 & $0.021^{* *}$ \\
\hline Pakistan & 11 & 6 & 38 & 5 & 28 & 0.444 & 0.700 \\
\hline Thailand & 12 & 1 & 2 & 11 & 76 & -2.903 & $0.001^{* * *}$ \\
\hline Vietnam & 23 & 0 & 0 & 21 & 231 & -4.014 & $<0.001^{* * *}$ \\
\hline Other countries & 29 & 7 & 124 & 17 & 176 & -0.743 & 0.466 \\
\hline World & 1,189 & 183 & 84,784 & 622 & 239,631 & -11.732 & $<0.001^{* * *}$ \\
\hline
\end{tabular}

Africa+ =Africa, Saudi Arabia and Yemen; Asia+ $=$ Central and South East Asia $\left({ }^{* * *}=P<0.01,{ }^{* *}=P<0.05,{ }^{*}=P<0.1\right)$.

Americas, significantly lower values of $P v \mathrm{PR}$ in rural areas were found. The $Z$ values indicate, however, that the differences observed in the Americas are weaker than in other regions. Moreover, the numbers of surveys available were much smaller in the Americas.

Those countries with at least ten urban-rural $P \nu P R$ value pairs and the other countries combined for each region (Africa+, Americas and Asia+) were tested further and the results are presented in Table 2. The trends found in most of the countries in Africa+ (Ethiopia, Yemen) and Asia+ (Bangladesh, Indonesia, India, Cambodia, Nepal, Thailand, Vietnam) were consistent with the global and regional findings, with significantly lower values of $P v \mathrm{PR}$ in urban areas. The relationships found between urban and rural $P v \mathrm{PR}$ values for the other countries in Africa+ (Sudan and other African countries) and Asia+ (Afghanistan, China, Pakistan and other Asian countries) were not significant. There are two countries (Ghana and Zambia) in Africa that have sufficient $P \nu$ PR surveys but are of entirely zero values, so were not listed. The results for the Americas are certainly not as conclusive as the relationships found in the other regions, with one country (Brazil) showing significant higher urban $P \nu \mathrm{PR}$ values, another country (Mexico) showing the reverse and the other American countries showing insignificant differences, though each were only based on a small number of $P v$ PR pairs.

The robustness analysis (Table 3 ) suggests that the overlap rate of rural surveys decreases as the spatial and temporal limits contract, while the patterns of $P v P R$ between urban and rural areas at global and regional scales are generally consistent. Thus, the method used to determine the relationship of $P$. vivax malaria transmission between urban and rural areas is robust and the effects of overlapping rural surveys on the results are minimal.

Figure 2 shows the boxplots for urban and rural $P \nu \mathrm{PR}$ surveys for individual cities whose extents were defined by the GRUMP-UE. The results indicate that the patterns among the 20 cities examined were less consistent with the global, regional and national patterns found. Seven cities (Alamata, Ethiopia; Jakarta, Batam, Kupang, Jambi and Ambon, Indonesia; Rourkela, India) were found to have significantly lower $P \nu \mathrm{PR}$ values in their urban extents than the surrounding rural areas; two cities (Qandahar, Afghanistan; Ariquemes, Brazil) were found to have significantly lower $P \nu \mathrm{PR}$ values in their 
Table 3 Robustness analysis of the Wilcoxon Signed Rank tests on urban-rural PvPR value pairs derived from various spatial and temporal limits

\begin{tabular}{|c|c|c|c|c|c|c|c|c|}
\hline \multirow[t]{2}{*}{ Region } & \multicolumn{2}{|c|}{100 km 5 years } & \multicolumn{2}{|c|}{$100 \mathrm{~km} 2$ years } & \multicolumn{2}{|c|}{$50 \mathrm{~km} 5$ years } & \multicolumn{2}{|c|}{$50 \mathrm{~km} 2$ years } \\
\hline & $Z$ & P-value & Z & P-value & Z & P-value & Z & P-value \\
\hline Africa+ & -5.670 & $<0.001^{* * *}$ & -5.623 & $<0.001^{* * *}$ & -5.644 & $<0.001^{* * *}$ & -5.397 & $<0.001^{* * *}$ \\
\hline Americas & 2.307 & $0.021^{* *}$ & 1.680 & $0.094^{*}$ & 0.486 & 0.631 & 0.730 & 0.471 \\
\hline Asia+ & -11.194 & $<0.001^{* * *}$ & -11.065 & $<0.001^{* * *}$ & -9.080 & $<0.001^{* * *}$ & -9.005 & $<0.001^{* * *}$ \\
\hline World & -11.732 & $<0.001^{* * *}$ & -11.555 & $<0.001^{* * *}$ & -10.052 & $<0.001^{* * *}$ & -9.757 & $<0.001^{* * *}$ \\
\hline No. pairs & \multicolumn{2}{|c|}{1,189} & \multicolumn{2}{|c|}{1,106} & \multicolumn{2}{|c|}{1,156} & \multicolumn{2}{|c|}{1,106} \\
\hline Mean No. R & \multicolumn{2}{|c|}{49.653} & \multicolumn{2}{|c|}{42.287} & \multicolumn{2}{|c|}{31.813} & \multicolumn{2}{|c|}{27.061} \\
\hline Overlap rate & \multicolumn{2}{|c|}{6.752} & \multicolumn{2}{|c|}{5.349} & \multicolumn{2}{|c|}{4.206} & \multicolumn{2}{|c|}{3.423} \\
\hline
\end{tabular}

Africa+ =Africa, Saudi Arabia and Yemen; Asia+ =Central and South East Asia; Mean No. R = Mean number of rural surveys for each urban-rural pair; Overlap rate $=\Sigma$ number of rural surveys paired to each urban survey/total number of rural surveys $\left({ }^{* * *}=P<0.01,{ }^{* *}=P<0.05,{ }^{*}=P<0.1\right)$.

surrounding rural areas (though again, the numbers of surveys were small). The remainder were either insignificant or of zero $P v \mathrm{PR}$ values.

\section{Dominant Anopheles vectors}

Figure 3A presents the results of Wilcoxon Signed Rank tests on $P v \mathrm{PR}$ values between GRUMP-UE defined urban and rural survey pairs stratified by the dominant Anopheles vectors of human malaria in the Asia-Pacific region. In this region, the patterns of lower $P$. vivax malaria transmission in urban areas are noticeable and consistent, with significantly higher rural $P v P R$ values found for most of the dominant Anopheles vector distributions (17 out of 19). Furthermore, insignificant differences between urban and rural areas (Anopheles balabacensis and Anopheles lesteri) were found in regions with small numbers of survey pairs.

Figure 3B shows the results of Wilcoxon Signed Rank tests on $P v \mathrm{PR}$ values between urban and rural survey pairs stratified by the dominant Anopheles vector distributions in Africa, Europe and the Middle East. PvPR surveys were only available for nine (of the 13) dominant Anopheles vectors. The consistent patterns of lower $P v \mathrm{PR}$ values in urban areas are not as evident as in AsiaPacific region. The differences of $P v P R$ between urban and rural areas are found to be statistically significant for only four (out of nine) dominant Anopheles vectors (Anopheles arabiensis, Anopheles funestus, Anopheles nili and Anopheles sergentii). The others were insignificant, while two of them (Anopheles melas and Anopheles sacharovi) have insufficient number of PvPR surveys.

Figure $3 \mathrm{C}$ presents the results of Wilcoxon Signed Rank tests for analyses stratified by dominant Anopheles vectors in the Americas. For two (out of nine) of the dominant Anopheles vectors no PvPR surveys fell within their extents. Unlike the patterns exhibited in the other regions, consistently higher $P v \mathrm{PR}$ values in urban areas were observed in this region, with most of the dominant Anopheles vectors (Anopheles albitarsis, Anopheles darlingi, Anopheles marajoara and Anopheles nuneztovari) showing significantly higher urban $P v \mathrm{PR}$ values. However, the numbers of survey pairs in this region are generally small.

More detailed statistical results for the three regions are provided in Additional file 1.

\section{Discussion}

The rapid urban transformation of the developing world [47] has and will continue to have a profound influence on the malaria landscape. The need for accurate and contemporary descriptions of populations at risk (PAR) has lead to several attempts to quantify the impact of urbanization on $P$. falciparum malaria transmission $[9,13,18]$. Knowledge is lacking however regarding the relationship between urbanization and $P$. vivax malaria transmission. In this study, the most contemporary and comprehensive database of $P v \mathrm{PR}$ surveys was used to explore the differences in $P$. vivax transmission between urban and rural areas.

Lower $P$. vivax malaria transmission in urban areas than surrounding rural areas was found globally, and in the Africa+ and Asia+ regions (Table 2), which corroborates previous findings that the urban environment is typically not suitable for malaria mosquito vectors [7-9]. The consistent patterns of significantly lower urban PvPR values found at the national scale in most of the countries in Africa+ and Asia+ further supports these findings (Table 2). However, the urban-rural survey pairs for each region are dominated by a few countries (e.g., Indonesia accounts for $65 \%$ of the Asia pairs and Sudan accounts for $45 \%$ of the Africa pairs), which make the patterns found at regional scale less informative. Distinct and inconsistent results were found in the Americas, with higher $P v \mathrm{PR}$ values in urban areas at the continental scale and for one particular country (Brazil) at the national scale. This result is probably due to the lack of $P v \mathrm{PR}$ surveys in this region, as surveys from the region only account for $4.1 \%$ of the $P v P R$ global 


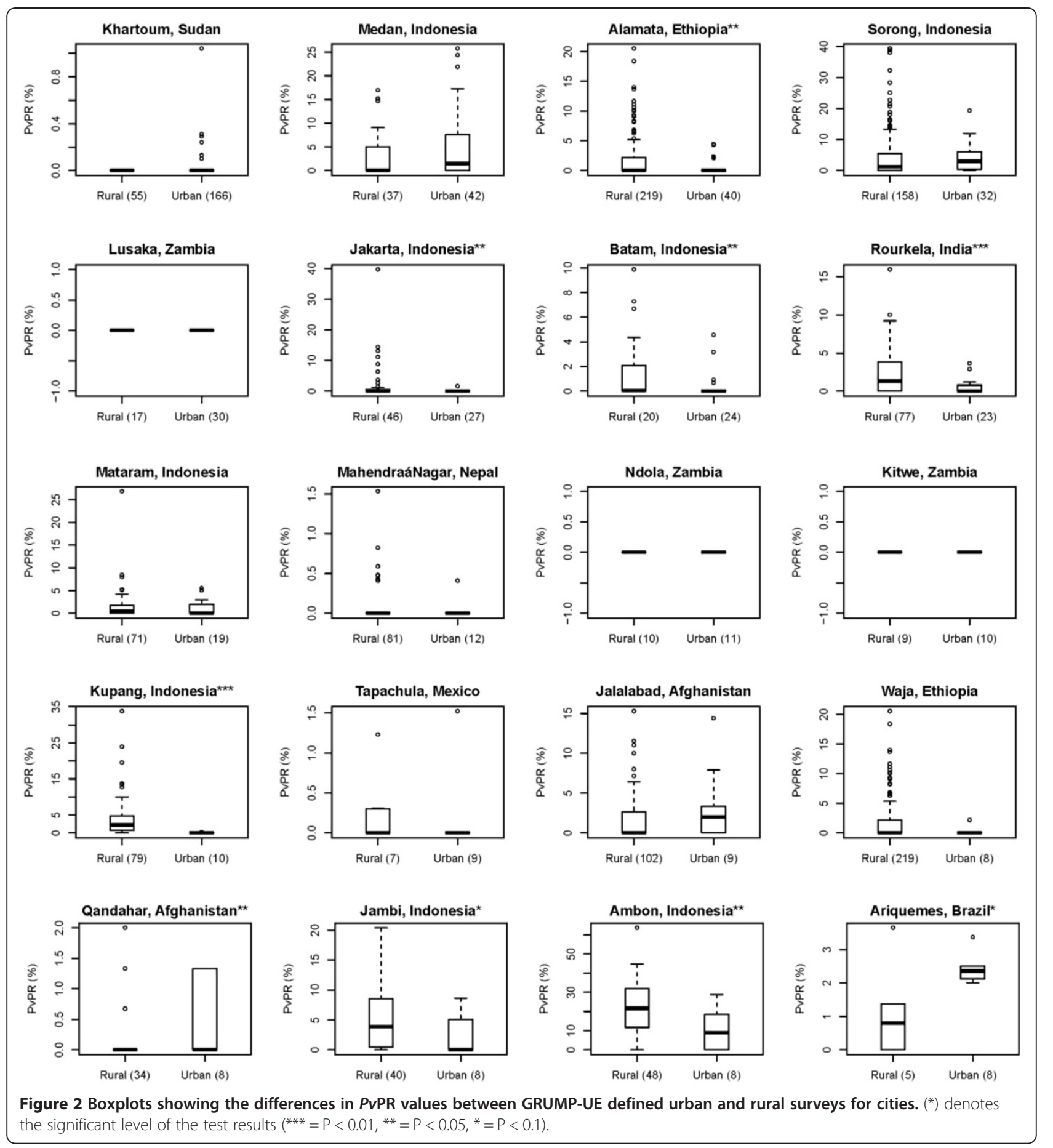

database. Getting extreme results is more likely when the numbers of surveys are small and only the rural $P v \mathrm{PR}$ surveys were averaged. There is also evidence suggesting that higher malaria transmission in some areas of Brazil was actually a result of rapid urbanization, during which settlements were built close to forest boundaries or along riversides and thus resulting in greater exposure to the malaria parasite for residents [48].
Figure 2 indicates that considerable heterogeneity exists when examining individual cities, with two cities (out of twenty) showing significantly lower $P \nu \mathrm{PR}$ in their surrounding rural areas, and seven cities showing significantly lower prevalence in urban areas. Thus, only nine of the twenty cities examined showed significant differences in transmission between urban and rural areas, and three showed zero prevalence both within and 


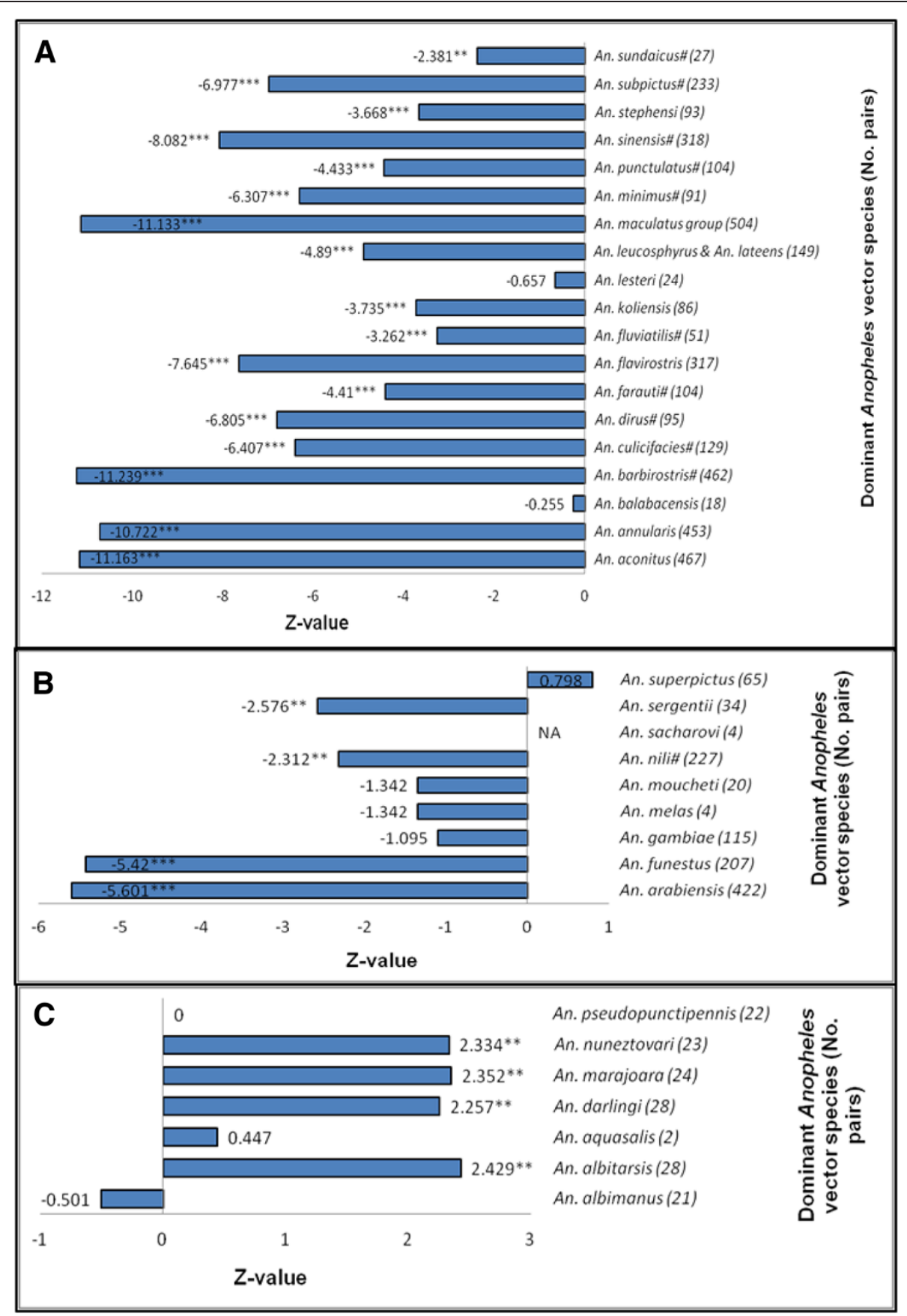

Figure 3 Bar charts showing the test results for the dominant Anopheles vectors of human malaria. Panel A shows the results of Wilcoxon Signed Rank tests on PVPR values between GRUMP-UE defined urban $(\mathrm{U})$ and rural(R) survey pairs for the dominant Anopheles vectors of human malaria in Asia-Pacific region. Panel $\mathbf{B}$ shows the results for the dominant Anopheles vectors in Africa, Europe and the Middle East. Panel $\mathbf{C}$ shows the results of Wilcoxon Signed Rank tests for the dominant Anopheles vectors in the Americas. ( $\left(^{\#}\right)$ denotes that a vector species is now recognized as a species complex. $\left(^{*}\right)$ denotes the significant level of the test $\left({ }^{* *}=P<0.01,{ }^{* *}=P<0.05,{ }^{*}=P<0.1\right)$.

around the urban areas. Compared to P. falciparum [18], therefore, the patterns of $P \nu \mathrm{PR}$ between urban and rural areas exhibit a higher level of heterogeneity. Several possible reasons include: 1) the wider transmission limits of $P$. vivax [15], but lower transmission intensity with many zero $P \nu \mathrm{PR}$ values in the database; 2 ) the wide distribution in Asia and high prevalence of Duffy negativity in Africa $[49,50]$; 3) relatively fewer $P v$ PR surveys available in the MAP database compared with a total of 22,212 $P$. falciparum parasite rate (PfPR) surveys in 2010 [23].

The $P v$ PR differences between urban and rural settings within the ranges of the dominant Anopheles vectors 
generally follows the patterns found in each region. This is partly because vector species that had sufficient urban-rural $P v \mathrm{PR}$ pairs within their extents usually cover a large portion of the region. An issue raised here is that the distributions of most of the vector species overlap substantially with each other. Thus, drawing conclusions about the patterns of individual vector species is difficult without considering such overlap. However, according to expert-opinion distribution maps of global DVS [25-27], the spatial relationships among those vector species are extremely complex and the interaction effects of them are beyond the scope of this analysis.

The GRUMP-UE was used to define urban areas here, though several alternative global urban maps exist [42]. Every global map suffers from different errors and uncertainties [42], and the GRUMP-UE map exhibits overestimation of large urban area extents, due to the blooming effect of NTL imagery [42,51]. This suggests that the $P v \mathrm{PR}$ urban values that were significantly higher than nearby rural ones found in the Americas and several other individual cities could actually be located in surrounding lower population density areas, as significantly higher malaria prevalence and entomologic inoculation rates in peri-urban areas compared to urban centers have been found in a number of studies $[9,13,18]$. To assess briefly this potential bias in the GRUMP-UE map, urban extents mapped using Moderate Resolution Imaging Spectroradiometer (MODIS) satellite sensor imagery $[40,41]$ were utilized to derive an alternative, more conservative, urban assignment for the PvPR surveys. Again, sets of spatially and temporally associated urban-rural pairs of $P v P R$ values were extracted and tested. The results show that, due to the more conservative nature of the classification, and the fact that only intensely urban areas were mapped [40,41], far fewer PvPR surveys were identified as urban and the differences in $P v P R$ between urban and rural areas were generally not significant (see Additional file 2). Such results highlight the differing outcomes that can occur through using differing definitions of urban, and that the effects of urbanization on $P$. vivax transmission may extend beyond the borders of intensely urban areas for most of the regions as a general trend of decreased $P \nu P R$ was found in urban areas. Another issue is that the GRUMP-UE map was produced in 2004 and some PvPR surveys may be misclassified as the urban extent changes through time. However, global urban maps that are updated regularly or that quantify urban extent change do not currently exist. Furthermore, the majority of the PvPR surveys were conducted between 2000 and 2010 (Table 1). Thus, it is reasonable to use the single time-point GRUMP-UE map in this analysis.

A range of human-induced environmental changes (e.g., deforestation, urbanization, water control projects and climate change) have been identified as drivers of 'emerging' and 'reemerging' diseases and the transmission of vector-borne and other infectious diseases [52-55]. Urbanization is usually recognized as one of the primary factors affecting vector-borne diseases [56] as it can not only provide residents with better access to healthcare and interventions $[4,5]$, and an environment generally less favorable for many disease vectors $[7,8]$, but can also modify land uses to expose humans to new pathogens and vectors [57]. While global and regional-scale results here show a general trend of decreased $P$. vivax transmission in urban areas, the heterogeneous impacts of urbanization on $P$. vivax malaria transmission at the city scale found in these analyses support increasing concerns of urban malaria problems in developing countries. Urbanization in these regions is often associated with poverty, poor water supplies and sanitation in peri-urban areas, providing breading sites for certain vectors [12]. Although malaria vectors are generally not favoured by urban environments, there is evidence highlighting the potential of malaria vectors in adapting to urban environments [58-60]. For example, Anopheles gambiae s.s. was found breeding in polluted water bodies in Lagos, Nigeria [59]. Furthermore, many studies suggested that urban agriculture is another important source for providing favourable breeding sites for malaria vectors in cities [61-64]. Increased malaria prevalence is often found in communities within a distance of $1 \mathrm{~km}$ from irrigated urban agriculture in Accra, Ghana [64], for example. Thus, malaria transmission in urban areas exhibits considerable spatial heterogeneity both between and within cities, depending on factors such as proximity to possible vector breeding habitats, urbanization level and socio-economic status [7,65]. Future work should aim to elucidate these drivers through examination of the disparity of $P$. vivax malaria transmission between and within cities using detailed household prevalence surveys and higher resolution urban maps.

In general, the results here highlight a consistent relationship at large scales between urban areas and lower $P$. vivax transmission, mirroring results found for $P$. falciparum, and pointing towards global declines in $P$. vivax transmission as urbanization permanently alters the receptivity of many areas. The findings suggest that these trends will likely continue to catalyze malaria declines on the path to a malaria free future.

\section{Additional files}

Additional file 1: Results of Wilcoxon Signed Rank tests on PvPR values between GRUMP-UE defined urban $(\mathrm{U})$ and rural(R) survey pairs for the dominant Anopheles vectors of human malaria.

Additional file 2: Results of Wilcoxon Signed Rank tests on PVPR values between MODIS defined urban (U) and rural(R) survey pairs for continents, countries and the World. 


\section{Abbreviations}

Africa+: Africa, Saudi Arabia and Yemen; Asia+: Central and South East Asia; DVS: Dominant vector species; GRUMP: Global Rural Urban Mapping Project; GRUMP-UE: GRUMP urban extent; MAP: Malaria Atlas Project; PfPR: $P$. falciparum parasite rate; PVAPI: $P$. vivax annual parasite incidence; PVPR: $P$. vivax parasite rate; PVMECs: $P$. vivax malaria endemic countries.

\section{Competing interests}

The authors declare that they have no competing interests.

\section{Authors' contributions}

AJT conceived the analyses. QQ and AJT developed the study design and QQ conducted the analyses. CAG, CMM and IRF gathered and processed the malaria prevalence data. PWG, CAG and SIH undertook construction of the vivax limits and dominant vector species dataset. All authors contributed to the writing of the manuscript. All authors read and approved the final manuscript.

\section{Acknowledgements}

The large global assembly of parasite prevalence data was critically dependent on the generous contributions of data made by a large number of people in the malaria research and control communities and these individuals are listed on the MAP website (http://www.map.ac.uk/ acknowledgements.html). AJT is supported by grants from the Bill and Melinda Gates Foundation (\#49446 and \#1032350) (http://www. gatesfoundation.org) and NIH/NIAID (U19AI089674). SIH is funded by a Senior Research Fellowship from the Wellcome Trust (\#095066) that also supports PWG. CLM is funded by a Biomedical Resources Grant from the Wellcome Trust (\#091835). IRFE is funded by grants from the University of Oxford-Li Ka Shing Foundation Global Health Program and the Oxford Tropical Network. AJT and SIH also acknowledge support from the RAPIDD program of the Science \& Technology Directorate, Department of Homeland Security, and the Fogarty International Center, National Institutes of Health (http://www.fic.nih.gov). This work forms part of the output of the Malaria Atlas Project (MAP, http://www.map.ox.ac.uk), principally funded by the Wellcome Trust, UK (http://www.wellcome.ac.uk). The funders had no role in study design, data collection and analysis, decision to publish, or preparation of the manuscript.

\section{Author details}

${ }^{1}$ Department of Geography and Emerging Pathogens Institute, University of Florida, Gainesville, FL, USA. ${ }^{2}$ Spatial Ecology and Epidemiology Group, Tinbergen Building, Department of Zoology, University of Oxford, South Parks Road, Oxford, UK. ${ }^{3}$ Eijkman-Oxford Clinical Research Unit, Jalan Diponegoro No. 69, Jakarta 10430, Indonesia. ${ }^{4}$ Department of Geography and Environment, University of Southampton, Highfield, Southampton, UK. ${ }^{5}$ Fogarty International Center, National Institutes of Health, Bethesda, MD 20892, USA.

Received: 18 August 2012 Accepted: 22 November 2012 Published: 5 December 2012

\section{References}

1. United Nations: World urbanization prospect, the 2011 revision. New York: United Nations; 2011

2. Vlahov D, Galea S: Urbanization, urbanicity, and health. J Urban Health 2002, 79:S1-S12

3. Vlahov D, Freudenberg N, Proietti F, Ompad D, Quinn A, Nandi V, Galea S: Urban as a determinant of health. J Urban Health 2007, 84:16-26.

4. Dye C: Health and urban living. Science 2008, 319:766-769.

5. Utzinger J, Keiser J: Urbanization and tropical health: then and now. Ann Trop Med Parasitol 2006, 100:517-533.

6. Moore M, Gould P, Keary BS: Global urbanization and impact on health. Int J Hyg Envir Heal 2003, 206:269-278.

7. Robert V, Macintyre K, Keating J, Trape J-F, Duchemin J-B, Warren M, Beier JC: Malaria transmission in urban sub-Saharan Africa. AmJTrop Med Hyg 2003, 68:169-176.

8. Donnelly M, McCall PJ, Lengeler C, Bates I, D'Alessandro U, Barnish G, Konradsen F, Klinkenberg E, Townson H, Trape J-F, Hastings I, Mutero C: Malaria and urbanization in sub-Saharan Africa. Malar J 2005, 4:12.
9. Hay SI, Guerra CA, Tatem AJ, Atkinson PM, Snow RW: Urbanization, malaria transmission and disease burden in Africa. Nat Rev Micro 2005, 3:81-90.

10. Trape JF: Malaria and urbanization in central africa: the example of brazzaville: part IV. Parasitological and serological surveys in urban and surrounding rural areas. Trans R Soc Trop Med Hyg 1987, 81:26-33.

11. Trape JF, Zoulani A: Malaria and urbanization in Central Africa: the example of Brazzaville: Part III: Relationships between urbanization and the intensity of malaria transmission. Trans R Soc Trop Med Hyg 1987, 81:19-25.

12. Knudsen $A B$, Sloff R: Vector-borne disease problems in rapid urbanization: new approaches to vector control. Bull World Health Organ 1992, 70:1-6.

13. Keiser J, Utzinger J, De Castro MC, Smith TA, Tanner M, Singer BH: Urbanization in sub-Saharan Africa and implication for malaria control. Am J Trop Med Hyg 2004, 71:118-127.

14. Mendis K, Sina B, Marchesini P, Carter R: The neglected burden of Plasmodium vivax malaria. Am J Trop Med Hyg 2001, 64:97-106.

15. Guerra CA, Howes RE, Patil AP, Gething PW, Van Boeckel TP, Temperley WH, Kabaria CW, Tatem AJ, Manh BH, Elyazar IRF, Baird JK, Snow RW, Hay SI: The international limits and population at risk of plasmodium vivax transmission in 2009. PLoS Negl Trop Dis 2010, 4:e774.

16. Price RN, Tjitra E, Guerra CA, Yeung S, White NJ, Anstey NM: Vivax malaria: neglected and not benign. Am J Trop Med Hyg 2007, 77:79-87.

17. Baird JK: Neglect of Plasmodium vivax malaria. Trends Parasitol 2007, 23:533-539.

18. Tatem A, Guerra C, Kabaria C, Noor A, Hay S: Human population, urban settlement patterns and their impact on Plasmodium falciparum malaria endemicity. Malar J 2008, 7:218.

19. Guerra CA, Snow RW, Hay Sl: Defining the global spatial limits of malaria transmission in 2005. Adv Parasitol 2006, 62:157-179.

20. Guerra CA, Snow RW, Hay SI: Mapping the global extent of malaria in 2005. Trends Parasitol 2006, 22:353-358.

21. Snow RW, Guerra CA, Noor AM, Myint HY, Hay SI: The global distribution of clinical episodes of Plasmodium falciparum malaria. Nature 2005, 434:214-217.

22. Hay SI, Guerra CA, Gething PW, Patil AP, Tatem AJ, Noor AM, Kabaria CW, Manh BH, Elyazar IRF, Brooker S, Smith DL, Moyeed RA, Snow RW: A world malaria map: Plasmodium falciparum endemicity in 2007. PLoS Med 2009, 6:e1000048.

23. Gething P, Patil A, Smith D, Guerra C, Elyazar I, Johnston G, Tatem A, Hay S: A new world malaria map: Plasmodium falciparum endemicity in 2010. Malar J 2011, 10:378

24. Foley DH, Rueda LM, Wilkerson RC: Insight into global mosquito biogeography from country species records. J Med Entomol 2007, 44:554-567.

25. Sinka M, Bangs M, Manguin S, Coetzee M, Mbogo C, Hemingway J, Patil A, Temperley W, Gething P, Kabaria C, Okara R, Van Boeckel T, Godfray HC, Harbach R, Hay S: The dominant Anopheles vectors of human malaria in Africa, Europe and the Middle East: occurrence data, distribution maps and bionomic precis. Parasit Vectors 2010, 3:117.

26. Sinka M, Bangs M, Manguin S, Chareonviriyaphap T, Patil A, Temperley W, Gething P, Elyazar I, Kabaria C, Harbach R, Hay S: The dominant Anopheles vectors of human malaria in the Asia-Pacific region: occurrence data, distribution maps and bionomic precis. Parasit Vectors 2011, 4:89.

27. Sinka M, Rubio-Palis Y, Manguin S, Patil A, Temperley W, Gething P, Van Boeckel T, Kabaria C, Harbach R, Hay S: The dominant Anopheles vectors of human malaria in the Americas: occurrence data, distribution maps and bionomic precis. Parasit Vectors 2010, 3:72.

28. Sharma VP: Fighting malaria in India. Current sci (Bangalore) 1998, 75:1127

29. Surendran SN, Ramasamyb R: Some characteristics of the larval breeding sites of Anopheles culicifacies species B and E in Sri Lanka. J Vector Dis 2005, 42:39-44.

30. Roberts D: Mosquitoes (Diptera: Culicidae) breeding in brackish water: female ovipositional preferences or larval survival? J Med Entomol 1996, 33:525-530.

31. Batra CP, Mittal PK, Adak T, Subbarao SK: Efficacy of Agnique MMF monomolecular surface film against Anopheles stephensi breeding in urban habitats in India. J Am Mosquito Contr 2006, 22:426-432.

32. Biswas D, Dutta R, Ghosh S, Chatterjee K, Hati A: Breeding habits of Anopheles stephensi Liston in an area of Calcutta. Indian J Malariol 1992, 29:195-198. 
33. Guerra CA, Gikandi PW, Tatem AJ, Noor AM, Smith DL, Hay SI, Snow RW: The Limits and intensity of Plasmodium falciparum transmission: implications for malaria control and elimination worldwide. PLOS Med 2008, 5:e38.

34. Malaria Atlas Project; www.map.ox.ac.uk.

35. Guerra CA, Hay S, Lucioparedes L, Gikandi P, Tatem A, Noor A, Snow R: Assembling a global database of malaria parasite prevalence for the malaria atlas project. Malar J 2007, 6:17.

36. Danko DM: The digital chart of the world project. Photogramm Eng Rem $\mathrm{S}$ 1992, 58:1125-1128.

37. Balk DL, Deichmann U, Yetman G, Pozzi F, Hay SI, Nelson A: Determining global population distribution: methods, applications and data. Adv Parasitol 2006, 62:119-156.

38. Hansen M, DeFries R, Townshend JRG, Sohlberg R: $1 \mathrm{~km}$ land cover classification derived from AVHRR. College Park. Maryland: The Global Land Cover Facility; 1998.

39. Elvidge CD, Baugh KE, Kihn EA, Kroehl HW, Davis ER: Mapping city lights with nighttime data from the DMSP operational linescan system. Photogramm Eng Rem S 1997, 63:727-734.

40. Schneider A, Friedl MA, Potere D: A new map of global urban extent from MODIS data. Environ Res Lett 2009, 4:4.

41. Schneider A, Friedl MA, Potere D: Monitoring urban areas globally using MODIS 500 m data: New methods and datasets based on urban ecoregions. Remote Sens Environ 2010, 114:1733-1746.

42. Tatem AJ, Noor AM, Hay SI: Assessing the accuracy of satellite derived global and national urban maps in Kenya. Remote Sens Environ 2005, 96:87-97.

43. Center for Internation Earth Science Information Network(CIESIN), Columbia University: International food policy research institute (IFPRI), the world band, centro international de agricultura tropical (CIAT), Global rural-urban mapping project (GRUMP): urban extents. Palisades, New York: CIESIN, Columbia University; 2004.

44. Hay SI, Sinka ME, Okara RM, Kabaria CW, Mbithi PM, Tago CC, Benz D, Gething PW, Howes RE, Patil AP, Temperley WH, Bangs MJ, Chareonviriyaphap T, Elyazar IRF, Harbach RE, Hemingway J, Manguin S, Mbogo CM, Rubio-Palis Y, Godfray HCJ: Developing global maps of the dominant Anopheles vectors of human malaria. PLoS Med 2010, 7:e1000209.

45. Gupta D, Bhatt R, Sharma R, Gautam A, Rajnikant AS: Intradomestic mosquito breeding sources and their management. Indian J Malariol 1992, 29:41-46.

46. Wilcoxon F: Individual comparisons by ranking methods. Biometrics 1945, 1:761-764.

47. Montgomery MR: The urban transformation of the developing world. Science 2008, 319:761-764.

48. Goncalves MJF, Alecrim WD: Non-planned urbanization as a contributing factor for malaria incidence in Manaus-Amazonas, Brazil. Rev Salud Pública 2004, 6:156-166.

49. Miller LH, Mason SJ, Clyde DF, McGinniss MH: The resistance factor to Plasmodium vivax in Blacks. New Engl J Med 1976, 295:302-304.

50. Howes RE, Patil AP, Piel FB, Nyangiri OA, Kabaria CW, Gething PW Zimmerman PA, Barnadas C, Beall CM, Gebremedhin A, Menard D, Williams TN, Weatherall DJ, Hay SI: The global distribution of the duffy blood group. Nat Commun 2011, 2:266.

51. Sutton PC: A scale-adjusted measure of "Urban sprawl" using nighttime satellite imagery. Remote Sens Environ 2003, 86:353-369.

52. Weiss RA, McMichael AJ: Social and environmental risk factors in the emergence of infectious diseases. Nat Med 2004, 10:70-76.

53. McMichael AJ: Environmental and social influences on emerging infectious diseases: past, present and future. Philos Trans $R$ Soc Lond B Biol Sci 2004, 359:1049-1058.

54. Patz JA, Daszak P, Tabor GM, Aguirre AA, Pearl M, Epstein J, Wolfe ND, Kilpatrick AM, Foufopoulos J, Molyneux D, Bradley DJ: Unhealthy landscapes: policy recommendations on land use change and infectious disease emergence. Environ Health Perspect 2004, 112:1092-1098.

55. Vora N: Impact of anthropogenic enviromental alterations on vectorborne diseases. Medscape J Med 2008, 10:238.

56. Molyneux DH: Patterns of change in vector borne diseases. Ann Trop Med Parasitol 1997, 91:827-840

57. Norris DE: Mosquito-borne diseases as a consequence of land use change. Ecohealth 2004, 1:19-24.
58. Chinery WA: Effects of ecological changes on the malaria vectors Anopheles funestus and the Anopheles gambiae complex of mosquitoes in Accra. Ghana. J Trop Med Hyg 1984, 87:191-206.

59. Awolola TS, Oduola AO, Obansa JB, Chukwurar NJ, Unyimadu JP: Anopheles gambiae s.s. breading in polluted water bodies in urban Lagos, southwestern Nigeria. J Vector Dis 2007, 44:241-244.

60. Antonio-Nkondjio C, Simard F, Awono-Ambene P, Ngassam P, Toto J-C, Tchuinkam T, Fontenille D: Malaria vectors and urbanization in the equatorial forest region of south Cameroon. Trans $R$ Soc Trop Med Hyg 2005, 99:347-354.

61. Afrane YA, Klinkenberg E, Drechsel P, Owusu-Daaku K, Garms R, Kruppa T: Does irrigated urban agriculture influence the transmission of malaria in the city of Kumasi, Ghana? Acta Trop 2004, 89:125-134.

62. Matthys B, Vounatsou P, Raso G, Tschannen AB, Becket EG, Gosoniu L, Cisse G, Tanner M, N'goran EK, Utzinger J: Urban farming and malaria risk factors in a medium-sized town in Côte d'Ivoire. Am J Trop Med Hyg 2006, 75:1223-1231.

63. Klinkenberg E, McCall P, Wilson M, Amerasinghe F, Donnelly M: Impact of urban agriculture on malaria vectors in Accra. Ghana. Malar J 2008, 7:151.

64. Stoler J, Weeks JR, Getis A, Hill AG: Distance threshold for the effect of urban agriculture on elevated self-reported malaria prevalence in Accra. Ghana. Am J Trop Med Hyg 2009, 80:547-554.

65. Mendez F, Carrasquilla G, Muñoz A: Risk factors associated with malaria infection in an urban setting. Trans R Soc Trop Med Hyg 2000, 94:367-371.

\section{doi:10.1186/1475-2875-11-403}

Cite this article as: Qi et al:: The effects of urbanization on global Plasmodium vivax malaria transmission. Malaria Journal 2012 11:403.

\section{Submit your next manuscript to BioMed Central and take full advantage of:}

- Convenient online submission

- Thorough peer review

- No space constraints or color figure charges

- Immediate publication on acceptance

- Inclusion in PubMed, CAS, Scopus and Google Scholar

- Research which is freely available for redistribution

Submit your manuscript at www.biomedcentral.com/submit
C) Biomed Central 